\title{
Querying the value of indiscriminate iron supplementation in pre-eclampsia: a cross-sectional study
}

\author{
Vinogrin Dorsamy ${ }^{1}$, Chauntelle Bagwandeen ${ }^{1}$, and J Moodley² \\ ${ }^{1}$ University of KwaZulu-Natal College of Health Sciences \\ ${ }^{2}$ University of KwaZulu-Natal Nelson R Mandela School of Medicine
}

July 10, 2021

\begin{abstract}
Objective To determine the prevalence and type of anaemia and its association with pre-eclampsia (PE) in pregnant South Africans of African ancestry. Design Cross-sectional study design Setting A regional hospital in KwaZulu-Natal, South Africa. Sample 671 women seeking antenatal care. Methods Participants had haemoglobin(Hb), anthropometric measurements, HIV status, blood pressure levels(BP) and proteinuria measured to determine PE. Iron studies and transferrin receptor levels were assessed in a subset and chi-square tests of association between normotensive and pre-eclampsia sub-groups and blood parameters were conducted. Results No difference in Hb concentration amongst the 4 groups $(\mathrm{F}(3,621)=0.981, \mathrm{p}<.001, \eta 2=.014)$ was observed. A chi-square test of association $(\chi 2(3)=6.674, \mathrm{p}=.083)$ showed no associations between study groups and having anaemia. The severity of anaemia did not vary amongst study groups $(\chi 2(12)=10.756, p=.550)$. Using ferritin, there was an association between the study groups having an iron deficiency, anaemia, both or neither $(\chi 2(3)=12.559, \mathrm{p}=.045)$ with a positive association between normotensive term and iron deficiency (adjusted residual(AR) 2.2) and positive association between early-onset PE(AR 2.4). Similar trends were found for transferrin and soluble transferrin receptor ferritin index. Twenty-two percent of the participants were not iron deficient. Conclusion Early-onset PE is associated with high iron status and not anaemia. Normotensive term pregnancies were associated with iron deficiency anaemia. Broad iron supplementation without adequate determination of iron deficiency in pregnant women needs to be revisited. Funding National Research Foundation (TTK170508230162), University of KwaZulu-Natal UCPD and Medical Research Council of South Africa(SIR Grant UNS14197). Keywords Anaemia, iron deficiency, pre-eclampsia
\end{abstract}

Querying the value of indiscriminate iron supplementation in pre-eclampsia: a cross-sectional study Vinogrin Dorsamy $^{1}$, Chauntelle Bagwandeen ${ }^{2}$, Jagidesa Moodley ${ }^{3}$

${ }^{1}$ Laboratory Medicine and Medical Sciences, College of Health Sciences, University of KwaZulu-Natal, South Africa

${ }^{2}$ Department of Public Health Medicine, School of Nursing and Public Health, University of KwaZulu-Natal, South Africa

${ }^{3}$ Women's Health and HIV, School of Clinical Medicine, University of KwaZulu-Natal, South Africa

Corresponding Author: Vinogrin Dorsamy

Address : Laboratory Medicine and Medical Sciences, College of Health Sciences, University of KwaZuluNatal, South Africa

Email Address : dorsamyv1@ukzn.ac.za

Email addresses of authors 
Chauntelle Bagwandeen (Bagwandeenc@ukzn.ac.za)

Jagidesa Moodley (jmog @ukzn.ac.za)

\section{Disclosure of interests}

The authors declare no competing interests.

\section{Abstract}

\section{Objective}

To determine the prevalence and type of anaemia and its association with pre-eclampsia (PE) in pregnant South Africans of African ancestry.

\section{Design}

Cross sectional study

\section{Setting}

A regional hospital in KwaZulu-Natal, South Africa.

\section{Sample}

671 women seeking antenatal care.

\section{Methods}

Participants had haemoglobin(Hb), anthropometric measurements, HIV status, blood pressure levels(BP) and proteinuria measured to determine PE. Iron studies and transferrin receptor levels were assessed in a subset and chi-square tests of association between normotensive and pre-eclampsia sub-groups and blood parameters were conducted.

\section{Results}

No difference in Hb concentration amongst the 4 groups (F $(3,621)=0.981, \mathrm{p}<.001, \eta 2=.014)$ was observed. A chi-square test of association $\left(\chi^{2}(3)=6.674, p=.083\right)$ showed no associations between study groups and having anaemia. The severity of anaemia did not vary amongst study groups $\left(\chi^{2}(12)=10.756, p=.550\right)$. Using ferritin, there was an association between the study groups having an iron deficiency, anaemia, both or neither $\left(\chi^{2}(3)=12.559, p=.045\right)$ with a positive association between normotensive term and iron deficiency (adjusted residual(AR) 2.2) and positive association between early-onset PE(AR 2.4). Similar trends were found for transferrin and soluble transferrin receptor ferritin index. Twenty-two percent of the participants were not iron deficient.

\section{Conclusion}

Early-onset PE is associated with high iron status and not anaemia. Normotensive term pregnancies were associated with iron deficiency anaemia. Broad iron supplementation without adequate determination of iron deficiency in pregnant women needs to be revisited.

\section{Funding}

National Research Foundation (TTK170508230162), University of KwaZulu-Natal UCPD and Medical Research Council of South Africa(SIR Grant UNS14197).

\section{Keywords}

Anaemia, iron deficiency, pre-eclampsia

\section{Tweetable abstract}


Iron deficiency is not associated with early onset pre-eclampsia and must be established before supplementation given

\section{Introduction}

The importance of addressing anaemia during pregnancy is well established ${ }^{1}$. Iron supplementation is routinely prescribed during antenatal care to prevent adverse maternal and perinatal outcomes ${ }^{2}$. While iron deficiency is the commonest cause of anaemia, and anaemia is associated with poor pregnancy outcomes, it is incorrect to assume that such associated outcomes are all related to iron deficiency ${ }^{3-5}$. Increasing evidence points to the contrary: iron overload or raised levels of the universal marker for anaemia, haemoglobin $(\mathrm{Hb})$, may also be responsible. Such outcomes may also be associated with tuberculosis, HIV, sexually transmitted infections, parasitic infections and obesity, which also play a role in the aetiology of anaemia ${ }^{6-9}$.

Current antenatal care, especially in low and middle income countries (LMIC's), mandates iron supplementation without establishing iron deficiency or type of anaemia ${ }^{10}$. Indiscriminate supplementation in pregnant women who may be iron replete, should be questioned since such practice may not only be wasteful, but harmful ${ }^{3,5,11}$. Iron is toxic and its regulation is carefully controlled to ensure that it is contained at all times, as increases in circulating and intracellular iron induces reactive oxidative species, cellular damage and ferroptosis ${ }^{5}$. In South Africa(SA), a LMIC, with a high burden of the above-mentioned conditions, the commonest direct cause of morbidity and mortality in pregnant women is pre-eclampsia $(\mathrm{PE})^{12}$, and like anaemia, is linked to preterm birth and small for gestational age(SGA) babies. While PE has been shown to be associated with severity of anaemia ${ }^{13}$, increased $\mathrm{Hb}$ is also a risk factor for these outcomes, suggestive of a 'Goldilocks' range for $\mathrm{Hb}$ levels: neither too high nor too low ${ }^{3,7,14}$. Haemoglobin levels alone may not reveal an association with $\mathrm{PE}$, which may be surreptitiously masked within a subtype of anaemia.

It is important that $\mathrm{Hb}$ and iron status be used to differentiate the type of anaemia present. The aim of this study was to delineate the prevalence and type of anaemia and its association with the spectrum of PE in SA, a country burdened by its high prevalence and concurrent epidemics of infectious and lifestyle diseases, using $\mathrm{Hb}$ levels in conjunction with iron markers. We delineated anaemia type by iron deficiency or anaemia of inflammation using markers such as ferritin, transferrin and its cognate receptor, in order to measure the association between the type of anaemia and the type of PE (early and late onset PE). We further established the burden of HIV and obesity using body mass index (BMI) and their associations with PE.

\section{Materials and Methods}

\section{Study design and setting}

This study was nested in a large, single-centre, prospective, population-based study that recruited pregnant women from a regional hospital providing maternity care services in Durban, South Africa. Participant recruitment occurred from May 2017 to February 2020. Pregnant women attending the hospital or its affiliated clinic for routine antenatal investigations ${ }^{10}$ or those presenting to the labour ward for a scheduled delivery or due to complications were requested to enrol in the study. The standard of care followed that described in the South African maternal care guidelines. In particular, as related to this study, Hb determination was made at the visit and iron supplementation was prescribed throughout pregnancy ${ }^{10}$. The sampling was purposive and non-probabilistic as participants were recruited into four groups based on the subtypes of PE, gestational age and timing of their antenatal visit.

Preeclampsia was diagnosed as sustained systolic blood pressure of [?] 140mmHg and a diastolic blood pressure of $90 \mathrm{~mm} \mathrm{Hg}$ taken on two occasions at least six hours apart; in addition, the diagnosis depended on the presence of one or more of the following: New onset proteinuria ( $1+$ on a urine dipstix) or $>30 \mathrm{mg} / \mathrm{dl}$ urine protein concentration or abnormal renal, and hepatic indices. Preeclampsia was also divided into

i) early onset $\mathrm{PE}$ (EOPE) as $\mathrm{PE}$ occurring before 34 weeks gestation and ii) late onset (LOPE) as that occurring [?] 34 weeks of gestation ${ }^{15}$.

The HIV status was recorded if known or a rapid HIV test was done as standard practice. 


\section{Inclusion and exclusion criteria}

South African pregnant women of African ancestry, 18 years of age or older were eligible for inclusion. Participants who had any pre-existing conditions or who were on any medications for hypertension or antiinflammatory conditions that could skew possible presentation of $\mathrm{PE}$ were excluded, as were those who agreed to participate but who were lost to follow-up, and where critical outcome data was not available despite tracing attempts. Due to challenges experienced with follow-up and delivery at sites other than the research site and due to the lockdown measures to combat the Covid-19 pandemic, instituted in March 2020, there was an unexpected attrition that was difficult to address, given the inability to conduct face to face visits. Attempts to account for loss to follow up were made by reconciling birth data from hospital chart data with labour ward birth data records, where available.

\section{Outcome measures}

The main outcomes of interest were normotensive pregnancy, early and late onset PE.

\section{Exposure measures .}

Haemoglobin concentration, mean cell volume (MCV), serum iron, ferritin, transferrin saturation, and serum transferrin receptor, as well as other haematological parameters were used as exposure variables.

Haemoglobin levels were determined by use of a haemoglobinometer or full blood count reports from patients' charts. Iron studies were analysed from serum samples using the Abbott Architect Ci 8200 chemiluminescent microparticle immunoassay (Abbott Diagnostics, Abbott Park, IL, USA) and soluble transferrin was determined from serum using the Roche Cobas 6000 electrochemiluminescence immunoassay (Roche Diagnostics, Mannheim, Germany).

Anaemia was defined according to the WHO classification of $<11 \mathrm{~g} / \mathrm{dL}^{1}$. Anaemia severity was grouped as: no anaemia raised $\mathrm{Hb}>13.2 \mathrm{~g} / \mathrm{dL}$; no anaemia: [?]11 g/dL; mild anaemia: $11 \mathrm{~g} / \mathrm{dl}<\mathrm{Hb}$ [?] 9.9g/dL; moderate anaemia: $9.9 \mathrm{~g} / \mathrm{dL}<\mathrm{Hb}<7.0$; severe anaemia [?] $7.0 \mathrm{~g} / \mathrm{dL}$. Haematological parameters were grouped according to their cut-points for determination of iron deficiency or iron deficiency anaemia. Ferritin levels in pregnancy were grouped as per Daru et al. ${ }^{16}$ and more recently Auerbach et al. ${ }^{17}$ where ferritin $<30$ $\mathrm{ng} / \mathrm{mL}$ with $\mathrm{Hb}<11 \mathrm{~g} / \mathrm{dL}$ is considered iron deficiency, anaemia while ferritin below $15 \mathrm{ng} / \mathrm{ml}$ in non-anaemic participants are classified as iron deficient. Similarly a cut-point of $>3 \mathrm{~g} / \mathrm{L}$ for transferrin or $37.68 \mu \mathrm{mol} / \mathrm{L}$ was used to define iron deficiency ${ }^{18,19}$. A raised C-reactive protein (CRP) was determined by cut-point $>$ $10 \mathrm{~g} / \mathrm{dL}^{20}$. Serum transferrin receptor/ log (ferritin) index used a cut-point of $1.4^{21}$.

\section{Statistics}

The number of participants in the study was validated using a priori power calculations with conservative effect size estimate of $\rho=0.02$, an $\alpha$ error of 0.05 and a power $(1-\beta)$ of $0.90^{22}$.

Statistical analysis was conducted using SPSS (IBM Corp. Released 2020. IBM SPSS Statistics for Windows, Version 27.0. Armonk, NY: IBM Corp). For each parameter evaluated, tests for normality were conducted using z-values of skewness and kurtosis and where these values fell within the range -1.96 to +1.96 , these were indicative of normal distribution. Where categorical variables were present $\chi^{2}$ tests were used and $\mathrm{p}<$ .10 was used to detect asymptotic significance. One-way ANOVAs and a Tukey's HSD post hoc test were used to identify between-group differences. A $p$ - value $<.05$ was considered statistically significant. Where data for certain parameters were missing, statistical analyses for these parameters were conducted using available data and noted as such in the (n) and degrees of freedom in the results.

Patient and public involvement (PPI)

There were no patient and public involvement strategies used in the study.

Results

\section{General Characteristics}


Approximately 1600 women were approached for enrolment. Six hundred and seventy-one $(\mathrm{n}=671)$ participants who met the inclusion criteria agreed to participate (Figure 1), with 410 women (61.1\%) falling into the normotensive group. The average age of the participants were 28.85 years old (SD 6.22).

Two hundred and sixty-one (38.9\%) participants presented with either EOPE $(n=141)$ or LOPE (n=120). The prevalence of anaemia was $35.5 \%$, with haemoglobin values missing for $6.9 \%$. One hundred and thirtyfive women $(20.1 \%)$ were mildly anaemic, $99(14.8 \%)$ were moderately anaemic and $4(0.6 \%)$ were severely anaemic. The prevalence of HIV infection was $46.1 \%(n=309)$. Table 1 summarises other relevant statistics.

\section{Maternal factors and Haematological indices}

There was no statistically significant difference in $\mathrm{Hb}$ concentrations amongst the four groups ( $\mathrm{F}(3,621)$ $\left.=0.981, p<.001, \eta^{2}=.014\right)$. A chi-square test of association $\left(\chi^{2}(3)=6.674, p=.083\right)$ showed no significant associations between the study groups and anaemia. The severity of anaemia did not vary amongst the groups $\left(\chi^{2}(12)=10.756, p=.550\right)$.

The chi-square test using anaemia/no anaemia and hypertensive/normotensive $2 \times 2$ table revealed $\chi^{2}(3)$ $=3.471, p=.064$ Cramer's V strength of association of 0.075 indicating a near significant association.

\section{Ferritin levels}

Using $\mathrm{Hb}$ cut-off and serum ferritin as a marker for iron deficiency in both anaemic and non-anaemic participants, out of 209 participants, 97 (46.4\%) had no anaemia and were not iron deficient, 24 (11.5\%) had no anaemia with iron deficiency and $61(29.2 \%)$ had iron deficiency anaemia, indicating that 27 women $(12.9 \%)$ were anaemic without signs of iron deficiency. Using a Fisher exact test comparing the study groups with the anaemia by ferritin group, $\chi^{2}(3)=12.559, p=.045$ there was a significant association between the study groups having iron deficiency, anaemia, both or neither. The adjusted residuals (AR) showed a negative association of the TermNT group with the non-iron deficient anaemia category (AR -2.2), and a negative association of the EOPE group with iron deficiency anaemia category (AR -2.2) but a stronger positive association with the non-iron deficient anaemia category (AR 2.4). As Figure 2 depicts, both the hypertensive groups had significantly higher frequencies of non-anaemic, non-iron deficient participants.

\section{Transferrin}

Similarly, using the combination of serum transferrin and $\mathrm{Hb}$ as a marker $(\mathrm{n}=559), 352(63 \%)$ were not anaemic, 51 (9.1\%) were anaemic without iron deficiency and $156(27.9 \%)$ had iron deficiency anaemia. A Pearson chi-square test for association between the term pregnancy groups and being either non-anaemic or anaemia with or without iron deficiency, classified by transferrin level (either less or greater than 36.7 $\mu \mathrm{mol} / \mathrm{L}$ showed that the groups were not independent from each other $\chi(4)=18.205, p=.001$, Cramer's $\mathrm{V}$ 0.155. Adjusted residuals were indicative of a significantly negative (AR -2.8) association of the EOPE group with iron deficiency anaemia and a negative association of non-iron deficiency anaemia with the TermNT group. There were no other associations between the other groups.

\section{Soluble transferrin receptor ferritin (STfR) index}

The soluble transferrin receptor (STfR)/ $\log$ (ferritin) index was calculated for 151 participants, resulting in $118(78.1 \%)$ classified as iron deficient regardless of anaemia status. $45(31.9 \%)$ were both anaemic and iron deficient and $65(46.1 \%)$ were iron deficient and not anaemic. Eighteen $(32.1 \%)$ and $9(17 \%)$

participants were not iron deficient in the EOPE and LOPE groups respectively. A chi-square test of association between anaemia/iron deficiency and term normotensive and both PE groups shows significant associations $\left(\left(\chi^{2}(12, \mathrm{~N}=114)=13.195, p=.040\right.\right.$, Cramer's $\left.\mathrm{V}=0.241\right)$, with adjusted residuals showing statistically significant positive associations between being anaemic without iron deficiency and the EOPE group (AR 2.3), with a negative trend of association between EOPE and iron deficiency anaemia (AR -1.5: not significant); being both anaemic and iron deficient and LOPE (AR 2.1); and iron deficiency with no anaemia and the normotensive group (AR 2.5); These results (Table 3) should be treated with caution as there was underrepresentation in the normotensive term group with only 5 cases analysed. 
When cross tabulating the index with severity of anaemia (anaemia level group), there were no dependent associations found $\left(\left(\chi^{2}(3, \mathrm{~N}=141)=2.585, p=.467\right.\right.$, Cramer's $\left.\mathrm{V}=0.135\right)$.

\section{Transferrin Saturation}

A chi-square test of association between anaemia/iron deficiency and TermNT and both PE groups shows significant associations $((\chi 2(6, \mathrm{~N}=387)=24.376, \mathrm{p}<.001$, Cramer's $\mathrm{V}=0.177)$. Adjusted residuals are provided in table 4 and indicate significant positive association of iron overload with EOPE and iron insufficiency in TermNT with a negative association between EOPE and reduced transferrin saturation.

\section{Body Mass Index}

BMI was statistically significantly different across all four groups $\mathrm{F}(3,583)=20.256, \mathrm{p}<001, \eta 2=.094)$ with means reported in Table 2. Post hoc analysis revealed that the FirstVisitNT group had a significantly lower BMI than the other groups $(\mathrm{p}<.001$ for all), and that there was no significant difference between the TermNT group and EOPE group $(\mathrm{p}=.577)$ despite a difference in mean gestational age. There was a significant difference between the TermNT and LOPE - BMI was $3.3 \mathrm{~kg} / \mathrm{m}^{2}$ lower $(p=.002)$ - but there was no difference between EOPE and LOPE $(p=.086)$.

\section{HIV}

A chi-square test of association between HIV and TermNT and both PE groups shows significant associations $\left(\chi^{2}(2, \mathrm{~N}=425)=9.086, p=.011\right.$, Cramer's $\left.\mathrm{V}=0.146\right)$. Adjusted residuals are provided in table 5. HIV infection in pregnancy was associated with EOPE and being HIV negative was more strongly associated with LOPE with no significance of HIV in normotensive pregnancies.

\section{Discussion}

\section{Main findings}

This study highlights the importance of identifying the cause of anaemia in pregnant populations as negative associations were found with iron deficiency, positive with anaemia unrelated to iron deficiency, and preeclampsia. The prevalence of anaemia was $35.5 \%$ with $20.1 \%$ being mildly anaemic, $14.8 \%$ moderately anaemic and $0.6 \%$ severely anaemic, with no difference between the normotensive and PE pregnancy groups There was no association between PE and severity of anaemia. While 350 participants were not anaemic $(52.2 \%), 37(5.5 \%)$ had a raised $\mathrm{Hb}(>13.2 \mathrm{~g} / \mathrm{dl})$. When evaluating the type of anaemia using a combination of ferritin and $\mathrm{Hb}$ level, iron deficiency anaemia was positively associated with normotensive term pregnancy, while EOPE was not associated with iron deficiency, independent of anaemia. Using iron markers such as transferrin and transferrin saturation showed similar trends, with a significant association between above normal saturation and PE. In the subset analysis of STfR-ferritin index, iron deficiency was found to be present in $118 / 151$ participants $(78.1 \%$ ) and iron deficiency anaemia in $31.9 \%$. Importantly, almost $22 \%$ of this subset was not iron deficient while $32.1 \%$ and $17 \%$ of the sample had no deficiency in the early and late pre-eclamptic groups respectively. Further investigation into iron saturation or overload revealed an association with EOPE. HIV prevalence was $46.1 \%$ and obesity was $50.3 \%$ and presence of both was significantly associated with PE.

\section{Strengths and limitations}

This is the first study, as far as we are aware, that distinguishes early and late onset PE and the type of anaemia in our population. Sampling is representative of the South African majority who share a similar socioeconomic status and burden of disease profile, and may be relevant to LMIC's regionally and globally. Although extrapolation to an affluent population might be limited, the conclusion and recommendations are equally applicable. The cross-sectional study design, normotensive early gestation participants lost to follow up, lack of maternal mortality statistics and limited birth outcome data impedes inference of cause and consequence. This study limits its definitions of types of anaemia to iron deficiency distinct from other causes collectively without exploring those in detail. 


\section{Interpretation}

Haemoglobin levels showed no significant association with either the presence or severity of anaemia. However, when using iron study markers such as ferritin and sTfR-ferritin index, associations were found with EOPE and either not being anaemic or iron deficient while normotensive pregnancy was associated with iron deficiency. The observed frequency of non-anaemia and hyperferritinaemia was significantly larger than the expected frequency in the EOPE group. Women with no anaemia and no iron deficiency were more frequently found in the EOPE group while anaemic women without iron deficiency were less associated with being normotensive and delivering at term. The LOPE group was significantly associated with anaemia regardless of iron deficiency, similarly evident when using the sTfR-ferritin index.

Our results that there is a hyperferritinaemia in PE are similar to other studies ${ }^{23-25}$. Raman et al. ${ }^{26}$ showed higher mean ferritin levels in pregnant women with pregnancy induced hypertension and PE, concluding that hyperferritinaemia may mask iron deficiency. Ferritin is an acute phase reactant ${ }^{27}$, and where there are infectious co-morbidities, iron deficiency may be hidden due to raised ferritin. van den Broek et al. ${ }^{18}$, when studying how well ferritin levels predicts bone marrow haemosiderin and true iron deficiency, found a 90\% sensitivity and $85.1 \%$ specificity using ferritin regardless of infection. We found a significant association related to the timing of $\mathrm{PE}$ as the association is strongest in the EOPE group, while no statistical variance in the means of CRP between the groups were noted. Thus, as Milman ${ }^{28}$ recommends, rather than blanket supplementation with iron, individual iron prophylaxis should be adjusted to serum ferritin levels in early pregnancy and suggest a potential benefit to measuring ferritin as an early marker of PE. Similarly, we found the use of transferrin confirmed the association found with ferritin that iron deficiency was negatively associated with the EOPE group.

A significant association between EOPE and having non-iron deficient anaemia was found in a smaller subset of participants using the sTfR-ferritin index, while LOPE was associated with anaemia and iron deficiency. The index is more sensitive for iron deficiency when there is concomitant inflammation ${ }^{21}$, and it detected that $20 \%$ of the sample had no iron deficiency.

Due to limited sampling of TermNT, we were unable to determine that association. Nevertheless, the results confirm the trends reported here and elsewhere $21,26,29$ for serum ferritin levels.

The prevalence of HIV in our study population was $46.1 \%$ and $50.3 \%$ of women were obese, an independent risk factor for PE. Both of these conditions are associated with anaemia of inflammation ${ }^{30}$, which if sustained, will lead to an iron deficient phenotype due to withholding of iron from what the body deems an infective insult, releasing Interleukin-6, which stimulates hepcidin release. This removes iron from circulation, thereby reducing efficient erythropoiesis ${ }^{23,31}$. Effectively, iron is then denied to the growing placenta and fetus which may impact on their growth ${ }^{5,23,32}$. The body storage capacity for iron is limited and sustained inflammatory conditions increase the risk of iron overload, especially when women are iron replete and are taking oral supplements ${ }^{5}$. This is toxic and has been shown to be associated with adverse birth outcomes ${ }^{3,5}$. Our study shows that both serum iron and transferrin saturation were increased in EOPE, indicating an association between iron overload and PE.

Iron overload has been associated with ferroptosis involving other organ systems ${ }^{5}$, notably those implicated in the pathophysiology of $\mathrm{PE}^{25,33-35}$, as well as gestational diabetes (GDM), a condition also associated with adverse birth outcomes ${ }^{29,36-38}$. While women who have anaemia should be treated, without understanding the cause of anaemia we risk subjecting women to iron overload. Using both ferritin and sTfr-ferritin index, iron overload was strongly associated with EOPE, while anaemia or iron deficiency was consistently associated with TermNT pregnancies, hence better birth outcomes. Poor birth outcomes is as associated with increased iron or raised haemoglobin as iron deficiency ${ }^{3,14,39}$ and iron overload or anaemia of inflammation is associated with $\mathrm{PE}^{5}$. Of concern is that when using the index, while $77.8 \%$ of the participants were iron deficient, by implication $22.2 \%$ were not. Hence a fifth of the population is being treated for a condition they do not have, with a potentially toxic substance ${ }^{5,33-35}$.

Conclusion and recommendations 
Our findings justify the need to revisit the present standard of determining anaemia (Hb alone), to ensure that we manage patients appropriately, with treatment dependent on cause rather than ubiquitous prescription of iron. Iron markers such as serum ferritin, at the least, may provide an insight into the true association between being non-anaemic and non-iron deficient and having EOPE. Further investigation is warranted where iron markers for storage, transport or use is measured to corroborate our findings. While the initial outlay of using such tests in resource-constrained settings may be baulked at, this will be outweighed by possible caesarean delivery and intensive care costs related to iatrogenic preterm delivery and distal therapeutic costs for long-term sequelae of iron overload.

Iron supplementation should be approached with caution in women at risk of PE and standard practise guidelines for antenatal care should consider targeted iron regulation based on the evidence presented in these and other studies. Health promotion and education on managing obesity, addressing the burden of infective causes of anaemia and mass treatment at the individual and population level to reduce the burden of parasitic infestations should be elevated as a health priority to reduce maternal and infant morbidity indices.

\section{Acknowledgements}

The authors wish to thank all participants who agreed to enrol in this study. We wish to acknowledge Melissa Bengu for data handling and processing for the study and Boikhutso Tlou for statistical analysis.

\section{Disclosure of interests}

The authors declare no competing interests.

\section{Contribution to authorship}

All authors (VD, CB, JM) contributed to the design of the study. VD and CB analysed and interpreted the quantitative data and all authors (VD, CB and JM) interpreted the data. VD drafted the first version of the article. All authors (VD, CB and JM) commented on drafts of the article and have read and approved the final version for publication.

\section{Detail of ethical approval}

The study received full ethical clearance from the Biomedical Research Ethics Committee at the University of KwaZulu-Natal (BREC552/16) in February 2016 and from the KwaZulu-Natal Department of Health and hospital management at the research site. The purpose of the study was explained to all pregnant women recruited who gave written informed consent to participate.

\section{Funding}

This study was funded by the South African National Research Foundation (NRF) Thuthuka grant (TTK170508230162) and the South African Medical Research Council (SIR Grant UNS14197), which included external peer review. The funders played no role in the conducting or research or writing of the manuscript.

\section{Table figure caption list}

Figure 1. Study groups: participants grouped according to the time of hospital visit, hypertensive state and gestational age.

Figure 2. Frequencies of anaemia coupled with iron deficiency as determined by specific cut-points of ferritin and $\mathrm{Hb}$ levels.

Table 1. Characteristics and parameter frequencies of all pregnant women enrolled in study

Table 2. Maternal variables and haematological indices per study group

Table 3. Cross tabulation of Anaemia and soluble Transferrin receptor ferritin index vs term and preeclamptic groups 
Table 4. Cross tabulation of transferrin saturation vs TermNT and Pre-eclampsia groups

Table 5. Cross tabulation of HIV vs normotensive term and PE Groups

\section{Data availability}

The data that support the findings of this study is part of a larger data set that is still being processed for further study. The data is not publicly available due to privacy or ethical restrictions.

\section{References}

1. WHO | Micronutrient deficiencies [Internet]. WHO. 2015 [cited 2015 Dec 18]. Available from: http://www.who.int/nutrition/topics/ida/en/

2. WHO | Daily oral iron supplementation during pregnancy [Internet]. WHO. [cited 2019 May 13]. Available from: http://www.who.int/elena/titles/review_summaries/daily-iron-pregnancy/en/

3. Dewey KG, Oaks BM. U-shaped curve for risk associated with maternal hemoglobin, iron status, or iron supplementation. Am J Clin Nutr. 2017 Dec;106(Suppl 6):1694S-1702S.

4. Fisher AL, Nemeth E. Iron homeostasis during pregnancy. Am J Clin Nutr. 2017 Dec 1;106(suppl_6):1567S-1574S.

5. Ng S-W, Norwitz SG, Norwitz ER. The Impact of Iron Overload and Ferroptosis on Reproductive Disorders in Humans: Implications for Preeclampsia. Int J Mol Sci. 2019 Jul 4;20(13).

6. Tunkyi K, Moodley J. Anaemia in pregnancy in a setting of high HIV prevalence rates. South Afr J Infect Dis. 2017 Dec;32(4):138-41.

7. Symington EA, Baumgartner J, Malan L, Wise AJ, Ricci C, Zandberg L, et al. Maternal iron-deficiency is associated with premature birth and higher birth weight despite routine antenatal iron supplementation in an urban South African setting: The NuPED prospective study. Shekhawat PS, editor. PLOS ONE. 2019 Sep 3;14(9):e0221299.

8. Kerkhoff AD, Lawn SD. Iron replacement therapy and anemia associated with chronic infectious diseases in sub-Saharan Africa. Clin Infect Dis Off Publ Infect Dis Soc Am. 2015 May 1;60(9):1438-9.

9. Hoque M, Hoque E, Kader S. Risk factors for anaemia in pregnancy in rural KwaZulu-Natal, South Africa: Implication for health education and health promotion. South Afr Fam Pract. 2009 Jan;51(1):68-72.

10. Naidoo DM. Guidelines for maternity care in South Africa. :174.

11. Casanueva E, Viteri FE. Iron and oxidative stress in pregnancy. J Nutr. 2003 May;133(5 Suppl 2):1700S1708 S.

12. Gathiram P, Moodley J. Pre-eclampsia: its pathogenesis and pathophysiolgy. Cardiovasc J Afr. $2016 ; 27(2): 71-8$.

13. Daru J, Zamora J, Fernández-Félix BM, Vogel J, Oladapo OT, Morisaki N, et al. Risk of maternal mortality in women with severe anaemia during pregnancy and post partum: a multilevel analysis. Lancet Glob Health. 2018 May 1;6(5):e548-54.

14. Murphy JF, O’Riordan J, Newcombe RG, Coles EC, Pearson JF. Relation of haemoglobin levels in first and second trimesters to outcome of pregnancy. Lancet Lond Engl. 1986 May 3;1(8488):992-5.

15. Chappell LC, Cluver CA, Kingdom J, Tong S. Pre-eclampsia. The Lancet [Internet]. 2021 May 27 [cited 2021 Jun 3];0(0). Available from: https://www.thelancet.com/journals/lancet/article/PIIS01406736(20)32335-7/abstract

16. Daru J, Allotey J, Peña-Rosas JP, Khan KS. Serum ferritin thresholds for the diagnosis of iron deficiency in pregnancy: a systematic review. Transfus Med Oxf Engl. 2017 Jun;27(3):167. 
17. Auerbach M, Abernathy J, Juul S, Short V, Derman R. Prevalence of iron deficiency in first trimester, nonanemic pregnant women. J Matern-Fetal Neonatal Med Off J Eur Assoc Perinat Med Fed Asia Ocean Perinat Soc Int Soc Perinat Obstet. 2021 Mar;34(6):1002-5.

18. van den Broek NR, Letsky EA. Etiology of anemia in pregnancy in south Malawi. Am J Clin Nutr. 2000;72(1):247s-56s.

19. Yamanishi H, Iyama S, Yamaguchi Y, Kanakura Y, Iwatani Y. Total Iron-binding Capacity Calculated from Serum Transferrin Concentration or Serum Iron Concentration and Unsaturated Iron-binding Capacity. Clin Chem. 2003 Jan 1;49(1):175-8.

20. Watts DH, Krohn MA, Wener MH, Eschenbach DA. C-reactive protein in normal pregnancy. Obstet Gynecol. 1991 Feb;77(2):176-80.

21. Punnonen K, Irjala K, Rajamaki A. Serum Transferrin Receptor and Its Ratio to Serum Ferritin in the Diagnosis of Iron Deficiency. Blood. 1997 Feb 1;89(3):1052-7.

22. G*Power 3: A flexible statistical power analysis program for the social, behavioral, and biomedical sciences | SpringerLink [Internet]. [cited 2021 Feb 27]. Available from: https://link.springer.com/article/10.3758/BF03193146

23. Toldi G, Stenczer B, Molvarec A, Takats Z, Beko G, Rigo J, et al. Hepcidin concentrations and iron homeostasis in preeclampsia. Clin Chem Lab Med. 2010 Oct;48(10):1423-6.

24. Brunacci F, Rocha VS, De Carli E, Esposito BP, Ruano R, Colli C. Increased serum iron in preeclamptic women is likely due to low hepcidin levels. Nutr Res N Y N. 2018;53:32-9.

25. Gutierrez-Aguirre CH, Garcia-Lozano JA, Trevino-Montemayor OR, Iglesias-Benavides JL, CantuRodriguez OG, Gonzalez-Llano O, et al. Comparative analysis of iron status and other hematological parameters in preeclampsia. Hematol Amst Neth. 2017 Jan;22(1):36-40.

26. Raman L, Pawashe AB, Yasodhara P. Hyperferritinemia in pregnancy induced hypertension and eclampsia. J Postgrad Med. 1992 Jun;38(2):65-7.

27. Cook JD, Flowers CH, Skikne BS. The quantitative assessment of body iron. Blood. 2003 May 1;101(9):3359-63.

28. Milman N, Byg K-E, Agger AO. Hemoglobin and erythrocyte indices during normal pregnancy and postpartum in 206 women with and without iron supplementation. Acta Obstet Gynecol Scand. 2000;79(2):8998.

29. Cheng Y, Li T, He M, Liu J, Wu K, Liu S, et al. The association of elevated serum ferritin concentration in early pregnancy with gestational diabetes mellitus: a prospective observational study. Eur J Clin Nutr. 2020 Jan 13;

30. Jordaan E, Van den Berg V, Van Rooyen F, Walsh C. Obesity is associated with anaemia and iron deficiency indicators among women in the rural Free State, South Africa. South Afr J Clin Nutr. 2020 Jul $2 ; 33(3): 72-8$.

31. Means RT. Hepcidin and Cytokines in Anaemia. Hematology. 2004 Oct 1;9(5-6):357-62.

32. Means RT. Iron Deficiency and Iron Deficiency Anemia: Implications and Impact in Pregnancy, Fetal Development, and Early Childhood Parameters. Nutrients. 2020 Feb 11;12(2).

33. Capelletti MM, Manceau H, Puy H, Peoc'h K. Ferroptosis in Liver Diseases: An Overview. Int J Mol Sci [Internet]. 2020 Jul 11 [cited 2021 May 30];21(14). Available from: https://www.ncbi.nlm.nih.gov/pmc/articles/PMC7404091/

34. Weiland A, Wang Y, Wu W, Lan X, Han X, Li Q, et al. Ferroptosis and its Role in Diverse Brain Diseases. Mol Neurobiol. 2019 Jul;56(7):4880-93. 
35. Yan H-F, Tuo Q-Z, Yin Q-Z, Lei P. The pathological role of ferroptosis in ischemia/reperfusion-related injury. Zool Res. 2020 May;41(3):220-30.

36. Khambalia AZ, Aimone A, Nagubandi P, Roberts CL, McElduff A, Morris JM, et al. High maternal iron status, dietary iron intake and iron supplement use in pregnancy and risk of gestational diabetes mellitus: a prospective study and systematic review. Diabet Med J Br Diabet Assoc. 2016 Sep;33(9):1211-21.

37. Zhang C, Rawal S. Dietary iron intake, iron status, and gestational diabetes. Am J Clin Nutr. 2017 Dec;106(Suppl 6):1672S-1680S.

38. Zhuang T, Han H, Yang Z. Iron, oxidative stress and gestational diabetes. Nutrients. 2014 Sep $25 ; 6(9): 3968-80$.

39. Haider BA, Olofin I, Wang M, Spiegelman D, Ezzati M, Fawzi WW, et al. Anaemia, prenatal iron use, and risk of adverse pregnancy outcomes: systematic review and meta-analysis. BMJ. 2013 Jun 21;346:f3443.

Table 1. Characteristics and parameter frequencies of all pregnant women enrolled in study

\begin{tabular}{|c|c|c|c|c|}
\hline Characteristic & Feature & & & \\
\hline & Normotensive & Hypertensive & & \\
\hline \multirow[t]{2}{*}{ Hypertensive status n (\%) } & $410(61.1)$ & $261(38.9)$ & & \\
\hline & $18-28$ & $29-39$ & $>=40$ & \\
\hline \multirow[t]{2}{*}{ Age (year group)- n (\%) } & $352(52.5)$ & $293(43.7)$ & $26(3.9)$ & \\
\hline & Primigravidae & Multigravidae & & \\
\hline \multirow[t]{2}{*}{ Gravidity } & $142(21.2)$ & $505(75.3)$ & & \\
\hline & First VisitNT & TermNT & EOPE & $L O P E$ \\
\hline \multirow[t]{2}{*}{$\mathrm{PE}$ group $-\mathrm{n}(\%)$} & $246(36.7)$ & $164(24.4)$ & $141(21)$ & $120(17$ \\
\hline & No Anaemia $\geq 11 \mathrm{~g} / \mathrm{dL}$ & Anaemia $<11.0 \mathrm{~g} / \mathrm{dL}$ & Missing & \\
\hline \multirow[t]{2}{*}{ Anaemia Total- n (\%) } & $387(57.7)$ & $238(35.5)$ & $46(6.9)$ & \\
\hline & No Anaemia Raised $H b>13.2 \mathrm{~g} / \mathrm{dL}$ & No Anaemia $>11 \mathrm{~g} / \mathrm{dL}$ & Mild [?] $10.9 \mathrm{~g} / \mathrm{dL}$ & Moder \\
\hline Anaemia level Group- n (\%) & $37(5.5)$ & $350(52.2)$ & $135(20.1)$ & $99(1$ \\
\hline BMI & $<18.5$ & $<25$ & $<30$ & {$[?] 40$} \\
\hline \multirow[t]{2}{*}{ BMI group- $\mathrm{n}(\%)$} & $77(11.5)$ & $70(10.4)$ & $160(23.8)$ & 256 \\
\hline & Negative & Positive & & \\
\hline HIV- n $(\%)$ & $362(53.9)$ & $309(46.1))$ & & \\
\hline
\end{tabular}

Values reported are frequencies and percentage. Where values do not add to $100 \%$ the missing percentage indicates where data was not available. PE -Pre-eclampsia, First VisitNT - First visit normotensive, TermNT - Term normotensive EOPE Early onset pre-eclampsia, LOPE Late onset pre-eclampsia, Anaemia defined according to WHO $<11 \mathrm{~g} / \mathrm{dL}$, BMI - Body mass index reported as raw weight / (height) $)^{2}$, C/S- Caesarean section, NVD -Normal vaginal delivery, IOL -Induction of labour, GA -gestational age, SGA -Small for gestational age, LGA -Large for gestational age

Table 2. Maternal variables and haematological indices per study group

\begin{tabular}{llllllll}
\hline & & First & & & & & \\
& VisitNT & TermNT & EOPE & LOPE & Total & $p$ \\
\hline Age & N & 246 & 164 & 141 & 120 & 671 & .098 \\
& Mean & 27.87 & 28.59 & 29.47 & 28.83 & 28.55 & \\
& Std. De- & 5.755 & 6.264 & 6.433 & 6.722 & 6.220 & \\
viation & & & & & &
\end{tabular}




\begin{tabular}{|c|c|c|c|c|c|c|c|}
\hline & & $\begin{array}{l}\text { First } \\
\text { VisitNT }\end{array}$ & TermNT & EOPE & LOPE & Total & $p$ \\
\hline \multirow{3}{*}{$\begin{array}{l}\mathrm{BMI} \\
\left(\mathrm{kg} / \mathrm{m}^{2}\right)\end{array}$} & $\mathbf{N}$ & 200 & 146 & 138 & 103 & 587 & $.000^{*}$ \\
\hline & Mean & 30.0885 & 33.1955 & 34.3007 & 36.5398 & 32.9836 & \\
\hline & $\begin{array}{l}\text { Std. De- } \\
\text { viation }\end{array}$ & 6.73127 & 6.16876 & 8.55735 & 7.90375 & 7.63541 & \\
\hline \multirow{3}{*}{$\begin{array}{l}\text { Haemogld } \\
(\mathrm{g} / \mathrm{dL}) \\
\text { at } \\
\text { recruit- } \\
\text { ment }\end{array}$} & & 215 & 163 & 138 & 109 & 625 & .437 \\
\hline & Mean & 11.154 & 11.245 & 11.388 & 11.330 & 11.260 & \\
\hline & $\begin{array}{l}\text { Std. De- } \\
\text { viation }\end{array}$ & 1.5079 & 1.3871 & 1.2725 & 1.2919 & 1.3900 & \\
\hline \multirow{3}{*}{$\begin{array}{l}\text { Maternal } \\
\text { Hb at } \\
\text { birth }\end{array}$} & $\mathbf{N}$ & 188 & 61 & 65 & 68 & 382 & .972 \\
\hline & Mean & 10.579 & 10.564 & 10.548 & 10.528 & 10.562 & \\
\hline & $\begin{array}{l}\text { Std. De- } \\
\text { viation }\end{array}$ & 0.8087 & 0.7253 & 0.8035 & 0.8162 & 0.7936 & \\
\hline \multirow{3}{*}{$\begin{array}{l}\text { Mean } \\
\text { Cell } \\
\text { volume } \\
\text { (fL) }\end{array}$} & $\mathbf{N}$ & 202 & 157 & 130 & 107 & 596 & .963 \\
\hline & Mean & 89.129 & 88.774 & 89.089 & 88.931 & 88.991 & \\
\hline & $\begin{array}{l}\text { Std. De- } \\
\text { viation }\end{array}$ & 6.9548 & 6.6766 & 6.2479 & 6.9563 & 6.7181 & \\
\hline \multirow{3}{*}{$\begin{array}{l}\text { ESR } \\
(\mathrm{mm} / \mathrm{hr})\end{array}$} & $\mathbf{N}$ & 203 & 148 & 122 & 98 & 571 & $.009^{*}$ \\
\hline & Mean & 34.55 & 35.16 & 40.17 & 42.04 & 37.19 & \\
\hline & $\begin{array}{l}\text { Std. De- } \\
\text { viation }\end{array}$ & 22.187 & 21.028 & 21.830 & 19.912 & 21.601 & \\
\hline \multirow{3}{*}{$\begin{array}{l}\text { CRP } \\
(\mathrm{mg} / \mathrm{L})\end{array}$} & $\mathbf{N}$ & 153 & 143 & 117 & 87 & 500 & .467 \\
\hline & Mean & 11.35 & 10.31 & 13.53 & 13.13 & 11.87 & \\
\hline & $\begin{array}{l}\text { Std. De- } \\
\text { viation }\end{array}$ & 24.147 & 15.494 & 15.553 & 12.684 & 18.210 & \\
\hline \multirow[t]{3}{*}{ RDW } & $\mathbf{N}$ & 159 & 154 & 124 & 105 & 542 & .373 \\
\hline & Mean & 14.741 & 15.177 & 14.827 & 14.938 & 14.923 & \\
\hline & $\begin{array}{l}\text { Std. De- } \\
\text { viation }\end{array}$ & 2.1557 & 2.6740 & 2.3265 & 1.7761 & 2.2905 & \\
\hline \multirow{3}{*}{$\begin{array}{l}\text { Mean } \\
\text { Cell Hb } \\
\text { Concen- } \\
\text { tration }\end{array}$} & $\mathbf{N}$ & 159 & 154 & 125 & 105 & 543 & .499 \\
\hline & Mean & 33.255 & 33.483 & 33.604 & 33.455 & 33.439 & \\
\hline & $\begin{array}{l}\text { Std. De- } \\
\text { viation }\end{array}$ & 1.5442 & 3.0385 & 1.0240 & 1.2105 & 1.9594 & \\
\hline
\end{tabular}




\begin{tabular}{|c|c|c|c|c|c|c|c|}
\hline & & $\begin{array}{l}\text { First } \\
\text { VisitNT }\end{array}$ & TermNT & EOPE & LOPE & Total & $p$ \\
\hline \multirow{3}{*}{$\begin{array}{l}\text { Serum } \\
\text { Transfer- } \\
\text { rin } \\
\text { Receptor } \\
(\mathrm{mg} / \mathrm{L})\end{array}$} & $\mathbf{N}$ & 35 & 8 & 66 & 64 & 173 & .514 \\
\hline & Mean & 3.909 & 3.288 & 3.359 & 3.553 & 3.539 & \\
\hline & $\begin{array}{l}\text { Std. De- } \\
\text { viation }\end{array}$ & 2.0434 & 0.9583 & 1.8863 & 1.6239 & 1.7935 & \\
\hline \multirow{3}{*}{$\begin{array}{l}\text { Serum } \\
\text { Iron }\end{array}$} & $\mathbf{N}$ & 216 & 155 & 134 & 111 & 616 & $.000^{*}$ \\
\hline & Mean & 14.1292 & 14.2329 & 18.6638 & 17.9153 & 15.8239 & \\
\hline & $\begin{array}{l}\text { Std. De- } \\
\text { viation }\end{array}$ & 7.72026 & 8.28140 & 13.61558 & 9.59026 & 9.93705 & \\
\hline \multirow{3}{*}{$\begin{array}{l}\text { Transferrin } \\
\text { umol/L }\end{array}$} & $\mathbf{N}$ & 191 & 144 & 129 & 108 & 572 & $.000^{*}$ \\
\hline & Mean & 38.67 & 46.98 & 39.016 & 42.39 & 41.54 & \\
\hline & $\begin{array}{l}\text { Std. De- } \\
\text { viation }\end{array}$ & 7.06 & 9.39 & 8.77 & 8.79 & 9.06 & \\
\hline \multirow{3}{*}{$\begin{array}{l}\text { Transferrin } \\
\text { Satura- } \\
\text { tion } \\
\%\end{array}$} & $\mathbf{N}$ & 190 & 143 & 131 & 113 & 577 & $.000^{*}$ \\
\hline & Mean & 19.24 & 15.94 & 26.01 & 22.07 & 20.52 & \\
\hline & $\begin{array}{l}\text { Std. De- } \\
\text { viation }\end{array}$ & 12.58 & 10.02 & 21.89 & 15.07 & 15.56 & \\
\hline \multirow{3}{*}{$\begin{array}{l}\text { Ferritin } \\
\mathrm{g} / \mathrm{dL}\end{array}$} & $\mathbf{N}$ & 52 & 32 & 79 & 82 & 245 & $.000^{*}$ \\
\hline & Mean & 34.38 & 28.63 & 75.23 & 38.84 & 48.29 & \\
\hline & $\begin{array}{l}\text { Std. De- } \\
\text { viation }\end{array}$ & 25.574 & 19.272 & 98.063 & 43.400 & 65.116 & \\
\hline \multicolumn{2}{|c|}{ STrFerrRatio N } & 33 & 5 & 57 & 56 & 151 & .021 \\
\hline & Mean & 3.2866 & 2.1309 & 2.0801 & 2.7248 & 2.5846 & \\
\hline & $\begin{array}{l}\text { Std. De- } \\
\text { viation }\end{array}$ & 2.49118 & 0.55494 & 1.30197 & 1.84298 & 1.85195 & \\
\hline \multicolumn{2}{|c|}{ AnaemiaGrouls } & 215 & 163 & 138 & 109 & 625 & .083 \\
\hline & Mean & 0.45 & 0.36 & 0.32 & 0.36 & 0.38 & \\
\hline & $\begin{array}{l}\text { Std. De- } \\
\text { viation }\end{array}$ & 0.498 & 0.482 & 0.468 & 0.482 & 0.486 & \\
\hline \multirow{3}{*}{$\begin{array}{l}\text { BMI } \\
\text { Group }\end{array}$} & $\mathbf{N}$ & 239 & 162 & 133 & 110 & 644 & $.000^{*}$ \\
\hline & Mean & 2.90 & 3.43 & 3.62 & 3.58 & 3.30 & \\
\hline & $\begin{array}{l}\text { Std. De- } \\
\text { viation }\end{array}$ & 1.211 & 1.108 & 0.950 & 1.252 & 1.183 & \\
\hline \multirow{2}{*}{$\begin{array}{l}\text { Anaemia } \\
\text { Severity } \\
\text { Group }\end{array}$} & $\mathbf{N}$ & 215 & 163 & 138 & 109 & 625 & .173 \\
\hline & Mean & 2.58 & 2.49 & 2.38 & 2.47 & 2.49 & \\
\hline
\end{tabular}




\begin{tabular}{lllllll}
\hline & $\begin{array}{l}\text { First } \\
\text { VisitNT }\end{array}$ & TermNT & EOPE & LOPE & Total & 0.851 \\
\hline $\begin{array}{l}\text { Std. De- } \\
\text { viation }\end{array}$ & 0.882 & 0.856 & 0.785 & 0.856 & & \\
\hline
\end{tabular}

*indicates significance. ESR-Erythrocyte sedimentation rate, CRP - C-reactive protein, BMI -Body mass index, RDW - Red cell distribution width, sTrFerrRatio -Soluble Transferrin $/ \log ($ ferritin) index

Table 3. Cross tabulation of Anaemia and soluble transferrin receptor/ferritin index vs term and pre-eclamptic groups.

\begin{tabular}{|c|c|c|c|c|c|c|c|c|c|c|c|}
\hline & & No & istreermot & istiveer & 1\$icePE & EOPE & EOPE & LOPE & LOPE & LOPE & Total \\
\hline & & $\mathrm{N}$ & $\%$ & $\mathrm{AR}$ & $\mathrm{N}$ & $\%$ & $\mathrm{AR}$ & $\mathrm{N}$ & $\%$ & $\mathrm{AR}$ & $\mathrm{N}$ \\
\hline Anaemia & Anaemia- & & $0.0 \%$ & -1.0 & 11 & $19.6 \%$ & .8 & 8 & $15.1 \%$ & -.4 & 19 \\
\hline sTfRFerr & Infdex & & & & & & & & & & \\
\hline & Def- & & & & & & & & & & \\
\hline & Anaemia + & & $0.0 \%$ & -.6 & 7 & $12.5 \%$ & $2.3^{*}$ & 1 & $1.9 \%$ & $-2.0^{*}$ & 8 \\
\hline & $\mathrm{Fe}$ & & & & & & & & & & \\
\hline & Def- & & & & & & & & & & \\
\hline & Anaemia- & & $100.0 \%$ & $2.5^{*}$ & 25 & $44.6 \%$ & -.4 & 23 & $43.4 \%$ & -.6 & 53 \\
\hline & $\mathrm{Fe}$ & & & & & & & & & & \\
\hline & Def + & & & & & & & & & & \\
\hline & Anaemia + & & $0.0 \%$ & -1.5 & 13 & $23.2 \%$ & -1.5 & 21 & $39.6 \%$ & $2.1^{*}$ & 34 \\
\hline & $\mathrm{Fe}$ & & & & & & & & & & \\
\hline & Def+ & & & & & & & & & & \\
\hline Total & Total & 5 & $100.0 \%$ & & 56 & $100.0 \%$ & & 53 & $100.0 \%$ & & 114 \\
\hline
\end{tabular}

Significant residuals are marked with an asterisk and shaded. AR -Adjusted residuals; EOPEEarly onset preeclampsia; LOPE - Late onset pre-eclampsia. The left column indicates the type of anaemia and + means condition present and - means absent

Table 4. Cross tabulation of transferrin saturation vs TermNT and pre-eclampsia groups Table 4 . Cross $t$

PE Group

TermNT

EOPE

LOPE

Total

Total

Significant residuals are marked with an asterisk and shaded. AR -Adjusted residuals; EOPEEarly onset preeclampsia; LOPE - Late onset pre-eclampsia. The left column indicates the type of anaemia and + means condition present and - means absent

Table 5. Cross tabulation of HIV vs normotensive term and PE Groups

\begin{tabular}{llllllllll}
\hline & & HIV - & HIV - & HIV - & HIV + & HIV + & HIV + & Total & Total \\
& & N & $\%$ & AR & N & $\%$ & AR & N & $\%$ \\
PE Group TermNT & 85 & $37.1 \%$ & -.7 & 79 & $40.3 \%$ & .7 & 164 & $38.6 \%$
\end{tabular}




\begin{tabular}{llllllllll} 
& EOPE & 66 & $28.8 \%$ & $-2.1^{*}$ & 75 & $38.3 \%$ & $2.1^{*}$ & 141 & $33.2 \%$ \\
& LOPE & 78 & $34.1 \%$ & $2.9^{*}$ & 42 & $21.4 \%$ & -2.9 & 120 & $28.2 \%$ \\
Total & Total & 229 & $100.0 \%$ & & 196 & $100.0 \%$ & & 425 & $100.0 \%$ \\
\hline
\end{tabular}

Significant residuals are marked with an asterisk and shaded. Minus (-) means negative magnitude. AR -Adjusted residuals; EOPE- Early onset preeclampsia; LOPE - Late onset preeclampsia.

\section{Hosted file}

Figure 1.docx available at https://authorea.com/users/424891/articles/529884-querying-thevalue-of-indiscriminate-iron-supplementation-in-pre-eclampsia-a-cross-sectional-study

Hosted file

Figure 2.docx available at https://authorea.com/users/424891/articles/529884-querying-thevalue-of-indiscriminate-iron-supplementation-in-pre-eclampsia-a-cross-sectional-study 